\title{
As Dinâmicas Arquitetônicas e Urbanísticas nos Videogames: do Lúdico à Construção de uma Inteligência Coletiva sobre os Espaços das Cidades
} The architectural and urban dynamics in video games: from the playful until the construction of a collective intelligence on the spaces of cities

\author{
Frederico Braida Rodrigues de Paula \\ Universidade Federal de Juiz de Fora, Brasil \\ frederico.braida@ufjf.edu.br
}

\author{
Mariana Alves Zancaneli \\ Universidade Federal de Juiz de Fora, Brasil \\ marianazancaneli@hotmail.com
}

\begin{abstract}
The aim of this paper is to show that video games, especially those played on a network, interconnected on the Internet can contribute to the formation of a collective intelligence on the spatiality of cities and urban lifestyles. Therefore, the article presents a mapping of the relationship between Videogames Design, Architecture and Urbanism, from four categories of analysis, showing the games as tools for building a collective intelligence, especially after widespread access to computers, Internet, smartphones and locative media.
\end{abstract}

Keywords: Videogames; Digital games; ArchitectureandUrbanism; Cities; Crowdthinking.

\section{Introdução}

Os jogos, sejam eles físicos ou digitais, ao longo da história, recorrentemente mostraram-se como parte importante das relações sociais, conformando importantes aspectos culturais (Huizinga, 2007). Assim, embora existam jogos individuais, o ato de jogar, muitas vezes, vincula-se aos grupos sociais.

Assim, pode-se considerar que os jogos estão diretamente relacionados ao pensamento coletivo, uma vez que, segundo Caillois (1990), "o jogo não é simplesmente uma distração individual". O autor ainda afirma que, por mais individualista que pareça o ato de se jogar, iríamos nos entediar rapidamente caso não existissem os adversários ou espectadores.

Caillois (1990), ao estabelecer uma análise dos tipos de jogos existentes, propõe uma divisão em quatro categorias, quais sejam: (1) agôn; (2) mimicry; (3) alea; e (4) ilinx. A partir dessa classificação, Ghisolfi e Vizioli (2013) sintetizam: "aalea diz respeito aos jogos de azar ou aleatoriedade, a mimicry aos jogos de imitação, onde o jogador incorpora personagens e ilinx se assenta na busca da vertigem com o intuito de destruir a estabilidade corpórea. Para a criação dos jogos digitais enfatizase o agôn".

Se, conforme mencionado, os jogos sempre participaram da vida das sociedades, no âmbito de suas conformações culturais, pode-se dizer que, com o advento dos computadores, os jogos digitais ganharam um grande destaque. Embora os jogos digitais tenham seus antecessores vinculados aos jogos desenvolvidos precariamente para suportes como televisões, na contemporaneidade, eles sofisticaram-se e passaram a ter, como suportes, telas sofisticadíssimas e de alta resolução.

Segundo Santaella (2013), é crescente a importância da "cultura gamer" na contemporaneidade e pode-se dizer que a gameficação, em alguma medida, tem afetado a vida de todos (WALZ; DETERDING, 2014).
No âmbito da Educação, por exemplo, temos assistido a uma proliferação dos cursos de Design de mídias, Design de Interfaces e, até, mais especificamente, Design de Jogos (ou [Vídeo]games).

Diante desse cenário ampliado e contemporâneo, verificam-se diversas imbricações entre os campos do Design de (Vídeo)games, da Arquitetura e do Urbanismo, uma vez que "muitos jogos de computador desenham inspiração para a arquitetura física. Como em um filme, certos lugares e configurações são favorecidos e retroativamente moldam nossas percepções. Jogadores de jogos de computador também experimentam o espaço físico de forma diferente e, assim, o usam de forma diferente. Novas possibilidades de absorção, como gestos e movimentos físicos substanciais estão fazendo essa hibridização do espaço virtual e real possível para o mercado de massa, colocando assim novas perguntas para os designers de games e tornando as disciplinas de construção e de espaços imaginados mais próximos. O design de jogos de computador não é mais apenas sobre as "Regras do Jogo", mas também sobre as "Regras do Lugar" (BORRIES; WALZ; BÖTTGER, 2007, tradução nossa).

Atualmente, de acordo com Kunkel (2015), "com a habilidade de manipular todas as interações que os jogadores podem ter em um jogo, os designers de videogames têm a oportunidade de moldar o modo como estes experienciam o espaço. Assim, estes profissionais frequentemente se voltam para a arquitetura para melhorar a jogabilidade e buscar inspiração para os ambientes construídos de seus mundos virtuais".

Em uma entrevista concedida a Manuel Saga, María Elisa Navarro,a arquiteta que supervisionou o desenvolvimento do jogo "Assassin'sCreed II", relata como foi sua participação na equipe multidisciplinar de criação, tornando-se mais um exemplo da relação que vem sendo estabelecida entre os jogos digitais e a arquitetura e o urbanismo (Saga, 2015). 
À guisa de Introdução, cabe ainda mencionar que este artigo é fruto de uma pesquisa que se desenvolveu, considerando as questões supracitadas, a partir do seguinte problema: Como podem os jogos digitais contribuir para a construção de um conhecimento sobre as dinâmicas arquitetônicas e urbanísticas? Portanto, o principal objetivo deste artigo é evidenciar que os videogames, sobretudo aqueles jogados em rede, interconectados via Internet, podem contribuir para a formação de uma inteligência coletiva sobre as espacialidades das cidades e os modos de vida urbanos.

\section{Procedimentos Metodológicos e Materiais: Videogames, Arquitetura e Urbanismo}

Este artigo é fruto de uma pesquisa qualitativa, de cunho bibliográfico e empírico, desenvolvida no âmbito do Grupo de Pesquisa das Linguagens e Expressões da Arquitetura, Urbanismo e Design (LEUAD), vinculado ao Departamento de Projeto, Representação e Tecnologia (DPRT), da Faculdade de Arquitetura e Urbanismo da Universidade Federal de Juiz de Fora (FAU/UFJF), sob a liderança do Prof. Dr. Frederico Braida.

Metodologicamente, em primeiro lugar, foi realizado um levantamento bibliográfico, que objetivou a aproximação do estado da arte das relações possíveis entre os campos do Design de videogames e da Arquitetura e Urbanismo. A principal base de dados consultada foi o Google Acadêmico, mas também foram realizadas buscas no SciELO e no Portal de Periódicos CAPES/MEC.

A revisão de literatura também incluiu alguns livros, quase sempre acessados a partir das buscas preliminares realizadas, que versam sobre o design de videogames, e, em especial, sobre as relações estabelecidas entre jogos digitais e arquitetura e urbanismo.

Do ponto de vista teórico, verificou-se que os jogos têm constituído, praticamente, um campo de saber próprio e específico. No que diz respeito das relações dos jogos com os objetos arquitetônicos e urbanísticos, pode-se afirmar que, por meio do engajamento que proporcionam, são capazes de contribuir, no âmbito da cibercultura (LÉVY, 2005), para a construção de uma inteligência coletiva sobre as cidades (LÉVY, 2000).

Em um segundo momento, levantou-se uma ampla lista de jogos que estabelecem relações entre arquitetura e urbanismo, a partir das seguintes categorias de análise: (1) arquitetura e urbanismo como cenário; (2) construção de espaços arquitetônicos e urbanísticos; (3) interatividade social no espaço digital; e (4) hibridismos entre o físico e o digital.

Deve-se ressaltar que essas categorias propostas não são estanques, mas sinalizam uma sistematização possível para os diferentes tipos de relações que podem ser estabelecidas entre os jogos digitais e a arquitetura e urbanismo. Cabe também evidenciar que as categorias são fruto do cruzamento dos dados levantados na pesquisa bibliográfica com as observações empíricas decorrentes dos acessos aos jogos pesquisados.

Por fim, foram realizados três estudos de caso: SimCity, The Sims e Cities: Skylines.A descrição desses jogos aponta para diferentes níveis de apropriações hibridizadas entre os universos dos videogames e da arquitetura e do urbanismo. A seleção desses jogos se deu devido à recorrência em que os mesmos aparecem na literatura e devido às suas fortes ligações com o universo arquitetônico e urbanístico.

\section{Jogos que articulam videogames e arquitetura e urbanismo}

Dentre os jogos digitais que articulam dois temas, podemos dividi-los em quatro categorias de análise, já mencionadas anteriormente. Essa divisão apresenta-se como uma proposta para sinalizar diferentes níveis de hibridização entre os dois campos.

$\mathrm{Na}$ primeira categoria, "Arquitetura e urbanismo como cenário", que compreende aqueles que possuem fortes influências da arquitetura e do urbanismo em seus cenários, podemos mencionar os casos da série Assassin's Creed, que conta hoje com doze títulos para diversas plataformas (UBISOFT.COM, 2016). A série de jogos se destaca por retratar cenários históricos da humanidade, contextualizando-se nas cidades de Florença, Veneza e Roma, na época dos anos 1400, na Paris da Revolução Francesa ou em Londres no período da Revolução Industrial.

É de se destacar que o jogo apresenta cenários muito realistas e fiéis à arquitetura e ao urbanismo de cada época, contando com diversos especialistas na equipe de desenvolvimento.

Outros jogos que se utilizam de cenários de época são The Saboteur, que se ambienta no cenário da Europa da Segunda Guerra Mundial e o jogo RedDeadRedemption, que retrata o período do velho oeste norte-americano. Outra franquia que chama a atenção por seu aspecto cenográfico é a série GTA (Grand Theft Auto), que já conta com onze títulos (ROCKSTARGAMES.COM, 2016) e com a representação de cidades de arquitetura tipicamente proveniente dos Estados Unidos, retratando a cidade como um todo, fazendo com que o jogador se aventure por ela, indo das áreas mais nobres até as periferias.

Outros jogos que seguem a mesma temática de cidades norte-americanas são a série Max Payne e Watch Dogs, que também têm por cenário a cidade.

Quanto à segunda categoria, "Construção de espaços arquitetônicos e urbanísticos", engloba todos os jogos que envolvem a construção de espaços arquitetônicos e urbanísticos. É nessa categoria que se encontram os seguintes jogos digitais: "The Sims", "SimCity" e "Cities: Skylines". Além deles, é possível citar também títulos como Minecraft, que "[...] permite aos usuários construir casas, cidades, bunkers subterrâneos e mundos virtuais utilizando cubos texturizados que representam diferentes materiais. O crude, plataforma cubista, cria uma paisagem pixelizada que se parece com uma versão rústica de um 
conjunto de LEGO. Além de seus próprios mundos de fantasia de formas livres, os usuários do Minecraft têm replicado praticamente todos os prédios famosos que existem, incluindo o Taj Mahal, a Casa Branca e o Burj Khalifa" (O'CONNELL, 2016).

Outro jogo relevante para ser citado é o Block'hood, que consiste em "um simulador que desafia os jogadores a criar uma comunidade funcional a partir de blocos de $1 \times 1 \times 1$ com programas variados. A interface apresenta gráficos simples mostrados a partir de vistas axonométricas que alternam ciclicamente entre dia e noite. Block'hood aborda o simples desejo de brincar com blocos e, então, torna estes vulneráveis às condições ambientais" (Lynch, 2016).

Quanto aos jogos que permitem uma "Interatividade social no espaço digital", podemos citar nomes como Second Life e Habbo Hotel, onde o jogador encarna um personagem digital para se comunicar com outros usuários em um mundo fictício; o próprio The Sims, que apresentou uma função de intercâmbio de personagens entre os jogadores, a partir de sua terceira edição, e as plataformas que permitem aos jogadores jogarem em modo multiplayer online, como a rede estabelecida entre os consoles PlayStation 3, PlayStation 4, Xbox 360 e Xbox One.

Por fim, a vertente dos jogos que misturam o meio físico e o digital pode ser representada pelas novas tecnologias dos videogames que se utilizam de movimentos físicos do jogador para que ações digitais sejam executadas pelo personagem no jogo, com os casos dos consoles Nintendo Wii, Xbox Kinnect e PlayStation Move. Outra tendência é a dos jogos educativos, como o exemplo do jogo REXplorer, citado na obra "Toward a ludicarchitecture: the space of play and games", de Steffen P. Walz (2010). O jogo é destinado aos turistas da cidade alemã de Regensburg e oferece missões virtuais, a partir de um aparelho, que só podem ser completadas se os jogadores (visitantes) percorrem um circuito pré-definido pelas construções importantes da cidade. Dessa forma, o conhecimento sobre a arquitetura e a história da cidade se torna algo lúdico e divertido.

Existe, no Brasil, uma proposta semelhante, desenvolvida em um projeto de pesquisa da IAU/USP São Carlos, coordenado

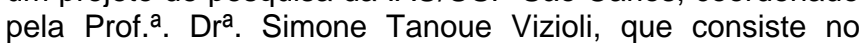
desenvolvimento de um jogo que busca a educação patrimonial das crianças da cidade (GHISOLFI; VIZIOLI, 2013). Também o LAURD/PROURB/FAU/UFRJ vem trabalhando em algumas vertentes, com criação de protótipos, de jogos que se articulam com as cidades e 0 patrimônio arquitetônico.

\section{"The Sims", "SimCity" e "Cities: Skylines" e a inteligência coletiva}

Pode-se dizer que, predominantemente a partir das observações empíricas levadas a cabo ao longo da pesquisa, o jogo The Simsconsiste em um simulador da vida real, onde o objetivo é fazer com que os personagens alcancem seus objetivos de vida (ou não, pois o jogo é bastante livre, nesse aspecto). Um dos pontos que sempre chamou a atenção para aqueles que gostam do tema arquitetura e criação, é a possibilidade de construir a casa dos personagens (os "Sims").

O jogo possibilita um alto nível de opções para criação de arquitetura, bem como os interiores das edificações, que podem ser privadas ou públicas. $O$ jogo conta com uma biblioteca de móveis, texturas, revestimentos e aparatos construtivos que o tornam bastante realista no aspecto do projeto arquitetônico. Para os jogadores mais avançados existe ainda a possibilidade de criação de objetos totalmente novos, permitindo que o jogador tenha uma liberdade criativa.

Um aspecto negativo, tratando-se do realismo do jogo no quesito projeto arquitetônico, é a não interferência do clima nas edificações, uma vez que o único prejuízo para a felicidade dos habitantes do ambiente é quando não se coloca uma janela nele, não importando se o cômodo está bem localizado ou algo do tipo.

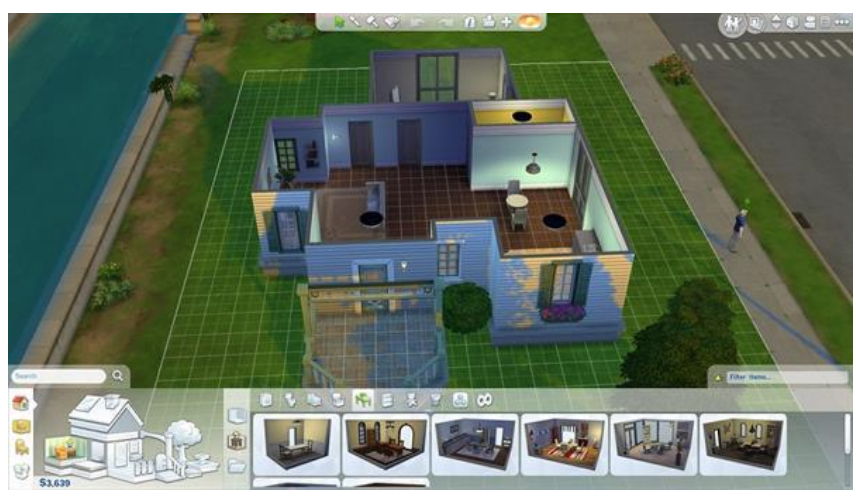

Figura 1:Interface do jogo The Sims4, com uma casa no modo construção. A barra na parte inferior apresenta várias possibilidades de se modificar a edificação, como telhados, paredes, fundações e elementos de mobiliário. Fonte: Game Zone. Disponível em http://www.mweb.co.za/games/view/tabid/4210/article/15 361/review-the-sims-4-one-step-forward-two-stepsback.aspx

Os jogos SimCitye Cities: Skylines apresentam um entretenimento voltado para o planejamento urbano, onde o objetivo é gerir uma cidade e não deixar os habitantes infelizes, bem como não deixar que a cidade vá à falência, de acordo com observações feitas. O primeiro SimCity foi lançado pela Maxis em 1989, nos Estados Unidos, sendo o último, até então, lançado em 2013. A série de jogos já passou por diversas versões, tendo sido o próprio The Sims lançado como um spin-off de SimCity(CARVALHO, 2015). Já Cities: Skylines é um jogo bem mais recente, tendo sido lançado em 2015, pela Colossal Order, na Finlândia. Em ambos, é possível que o jogador comande uma cidade, enfrentando problemas reais delas como trânsito, transporte público, serviços, indústrias, poluição, tudo objetivando a felicidade da população bem como respeitando o orçamento da cidade, a partir de observações realizadas jogando-os.

Os dois jogos refletem muito bem os problemas citados acima, porém abordam muitos aspectos de cidades 
provenientes do país onde foram desenvolvidos. SimCity, por exemplo, apresenta uma dinâmica onde os cidadãos que possuem uma condição financeira confortável, não utilizam o transporte público.

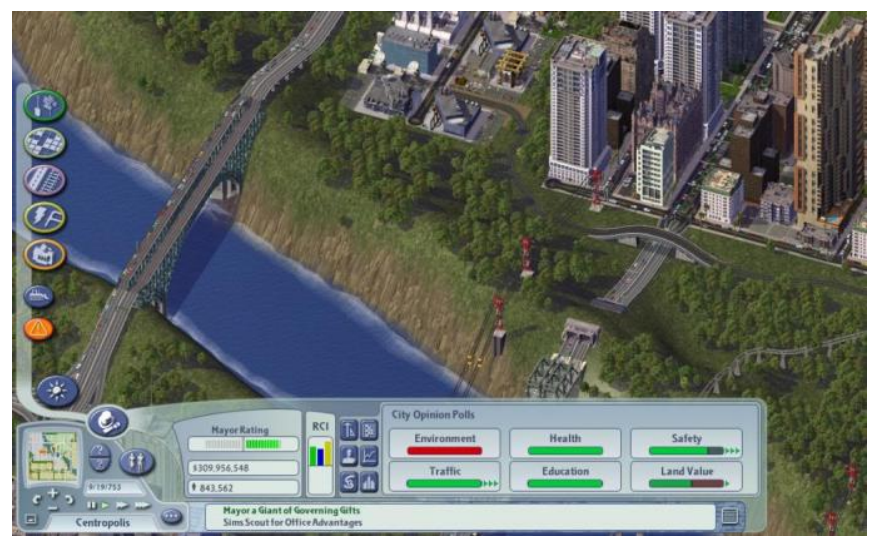

Figura 2:Interface do jogo SimCity 4, com uma cidade em desenvolvimento. As barras nas partes inferior e esquerda apresentam as estatísticas da cidade bem como as ferramentas de gerenciamento da mesma. Fonte:Simtropolis. Disponível em http://community.simtropolis.com/forums/topic/58188new-ui-time-for-a-change/

Já em Cities: Skylines, todos os cidadãos utilizam todos os meios de transporte oferecidos pelo jogo, refletindo muito bem as características das cidades estadunidenses (no caso deSimCity) e finlandesas. Outro ponto, ainda referente a essa questão, é que, justamente por na Finlândia a desigualdade social ser praticamente inexistente, todas as casas possuem o mesmo padrão, já nas casas de SimCity existem diferentes demandas por diferentes padrões de residências, indo das mais humildes às mais ricas.

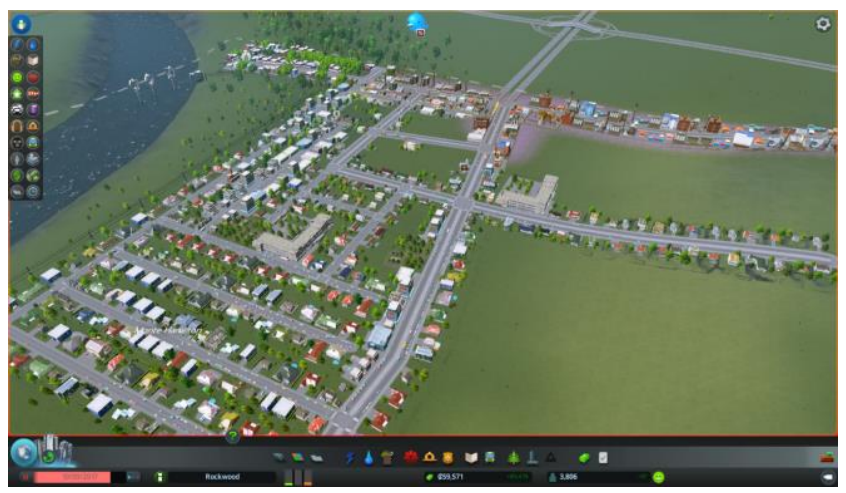

Figura 3:Interface do jogo Cities: Skylines, com uma cidade em desenvolvimento. Os botões à esquerda permitem ao jogador gerenciar várias opções da cidade, como trânsito, abastecimento de água e energia, dentre outros. Fonte: Acervo Pessoal.

\section{Resultados}

As análises descritivas e comparativas buscaram ressaltar as principais características de cada um dos jogos, evidenciando-se como se dão as relações e experiências cognitivas das espacialidades e da imersão proporcionada aos jogadores, apontando as possibilidades e ferramentas que cada jogo oferece para a construção de uma inteligência coletiva sobre as cidades.

Como resultados, podemos dizer que foram detectadas as seguintes diferenças e semelhanças entre os jogos: primeiramente, os três jogos são capazes de representar de forma lúdica e atrativa algumas das realidades encontradas por quem desenvolve planejamento de edificações ou de cidades, apresentando muitas possibilidades de desenvolvimento criativo e de ordem prática; ambos ainda apresentam algumas deficiências quanto às proximidades com a realidade, no entanto, acredita-se que, pelo fato de não terem sido concebidos para esse fim, o de projetar, mas, ao mesmo tempo, consistem em boas ferramentas para a difusão da arquitetura e do urbanismo no meio leigo e até mesmo é uma forma de tornar o ato de projetar algo mais divertido para os profissionais.

Em termos gerais, a partir da observação empírica dos jogos utilizados para a categorização e, mais especificamente, das análises descritivas empreendidas dos três jogos mencionados na seção anterior, tem-se que: os jogos que abordam a arquitetura e urbanismo como cenário têm o potencial para difusão de uma cultura arquitetônica e urbanística, por exemplo, vinculada ao patrimônio (trabalho de pesquisa já desenvolvido e em desenvolvimentos por pesquisadores da área de arquitetura e urbanismo em universidades brasileiras); os jogos de construção têm o potencial para desenvolver a criatividade e crítica projetual; os jogos que mesclam o físico e o virtual possibilitam a exploração da cidade, por exemplo, por meio da realidade aumentada (sobretudo com o auxílio de mídia locativas, graças à ubiquidade); e, por fim, os jogos de sociabilidade no meio digital proporcionam estratégias coletivas de resolução de problemas, contribuindo, verdadeiramente para uma construção de uma inteligência coletiva.

\section{Discussão}

Ao final, a partir dos dados coletados e das análises empreendidas, pode-se concluir que, embora haja níveis de engajamento diferenciados, todos os jogos levantados contribuem para a formação da inteligência coletiva sobre as espacialidades arquitetônicas e urbanísticas.

Assim, espera-se que este artigo possa contribuir, ainda que preliminarmente, com um mapeamento das relações entre 0 Design de videogames, a Arquitetura e o Urbanismo, evidenciando os jogos como ferramentas para construção de uma inteligência coletiva, sobretudo após a massificação dos computadores, da Internet, dos smartphones e das mídias locativas.

A partir dos resultados alcançados, esperamos, também, suscitar possíveis desdobramentos da utilização de jogos no âmbito da Arquitetura e do Urbanismo, desenvolvidos tanto para iniciados (profissionais e estudantes) quanto para 0 público leigo (difusão do conhecimento). 
O presente artigo vislumbrou, portanto, revelar também a potencialidade de novos estudos para o tema, que se mostrou tão relevante para o campo da arquitetura e do urbanismo, que tem muito a se aproveitar do meio digital lúdico, afim de ampliar a discussão sobre o planejamento urbano e também o projeto de edificações em geral, atingindo vários públicos, desde aqueles que já estão inseridos no meio como aqueles que apenas se interessam pelo tema e até mesmo curiosos que venham a jogar para se divertir e se interessem pela arquitetura e urbanismo.

\section{Agradecimentos}

Agradecemos à Fundação de Amparo à Pesquisa do Estado de Minas Gerais (FAPEMIG) que tem financiado parte das pesquisas desenvolvidas no âmbito do Grupo de Pesquisa LEAUD/UFJF, em especial pelos termos de outorga TEC PPM-00766-15 e TEC - APQ-01041-14.

\section{Referências}

Borries, F., Walz, S. P., Böttger, M. (Ed.) (2007). Space Time Play: Computer Games, Architecture and Urbanism: The Next Level. Basel: Birkhäuser.

Caillois, R. (1990). Os jogos e os homens: A máscara e a vertigem. Lisboa: Livros Cotovia.

Carvalho, T. (2015). SimCity: veja curiosidades sobre o popular simulador de cidades. Tech tudo. Disponível em http://www.techtudo.com.br/noticias/noticia/2015/01/simcity-vejacuriosidades-sobre-o-popular-simulador-de-cidades.html

Ghisolfi, E. M. O., Vizioli, S. T. (2013). A arquitetura patrimonial através dos jogos digitais

Huizinga, J. (2007). Homo ludens: o jogo como elemento da cultural. São Paulo: Perspectiva.

Kunkel, P. (2015). De Minecraft a Assassin'sCreed II: a arquitetura virtual de seis jogos de videogame. Arch Daily: o site de arquitetura mais visitado do mundo. Disponível em http://www.archdaily.com.br/br/769409/qual-video-game-tem-amelhor-arquitetura

Lévy, P. (2000). A Inteligência Coletiva. São Paulo: Edições Loyola.

Lévy, P. (2005). Cibercultura. São Paulo: Ed. 34.

Lynch, P. (2016). Block'hood: O jogo que testará suas habilidades de arquiteto e urbanista. ArchDaily Brasil. (Trad. Baratto, Romullo) .Acessado em: 11 jul 2016. Disponível em: <http://www.archdaily.com.br/br/784258/blockhood-o-jogo-quetestara-suas-habilidades-de-arquiteto-e-urbanista>.

Página oficial do jogo Watch Dogs na internet. 2014. Disponível em https://www.ubisoft.com/pt-BR/game/watch-dogs-2/

Página oficial da Rockstar na internet. Disponível em http://www.rockstargames.com/games\#/?platform=12\&all=true

Saga, M. (2015). María Elisa Navarro, a arquiteta que supervisionou o desenvolvimento de Assassin'sCreed II. Arch Daily: o site de arquitetura mais visitado do mundo. Disponível em http://www.archdaily.com.br/br/767677/maria-elisa-navarro-aarquiteta-que-assessorou-o-desenvolvimento-de-assassins-creed-ii

Santaella, L. (2013). Comunicação Ubíqua: Repercussões na Cultura e na Educação. São Paulo: Paulus.

Walz, S. P. (2010). Toward a Ludic Architecture: the Space of Play and Games. Pittsburgh, PA: ETC Press.

Walz, S. P.; Deterding, S. (2014). The Gameful World: Approaches, Issues, Applications. Cambridge, MA: MIT Press. 